\title{
Currículo universitário: do México ao Brasil neoliberais
}

\author{
Dostoiewski Mariatt de Oliveira Champangnatte
}

Resumo: O objetivo deste estudo foi discutir e comparar percepções e ações curriculares de professores universitários mexicanos e brasileiros. Contextualizando as realidades socioeconômicas dos dois países e, principalmente, as políticas governamentais voltadas ao ensino superior, observa-se, nas várias falas dos professores, uma abordagem simplista de currículo, significando-o apenas como preocupações de conteúdos administrados em disciplinas e planos de ensino. Aspectos da realidade social, política e econômica são desatrelados do pensamento e prática curriculares, onde o maior objetivo se tornou a adequação ao mercado de trabalho. Nota-se, direta e indiretamente, influências do pensamento e práticas neoliberais no posicionamento desses professores tanto quanto ao currículo como com a própria funcionalidade do ensino superior, refletindo e reproduzindo, em seus discursos e práticas, as políticas governamentais neoliberais vigentes.

Palavras-chave: Currículo universitário. Políticas. Neoliberalismo.

\section{University curriculum: from neoliberal Mexico to neoliberal Brazil}

Abstract: This paper's purpose is to discuss and compare curricular perceptions and actions of Brazilian and Mexican university professors. It contextualizes the two countries' socioeconomic reality and mainly the higher education governmental policies. It is possible to observe in the professors' discourse an approach to curriculum, which regards it only as a concern with the subjects taught syllabus design. Aspects of social, economic and political contexts are absent from curricular thought and practice, with is main concern being the adaptation to the labor market. It is also possible to notice, directly or indirectly, influences of neoliberal thoughts and practices in these professors' position with regard to curriculum and to the very functionality of the higher education, reflecting and reproducing, in their discourses and practices, the current neoliberal government policies.

Key words: University curriculum. Policies. Neoliberalism. 


\section{Introdução}

A pesquisa em educação superior no Brasil foi bastante incentivada a partir da criação do grupo de trabalho 11 (GT-11) Política de Educação Superior, integrante da Associação Nacional de Pós-Graduação e Pesquisa em Educação (ANPEd). De acordo com Fávero (2002), o primeiro encontro ocorreu no ano de 1982, durante a quinta reunião anual da ANPEd. O grupo, que já nasceu discutindo a reforma estrutural da universidade, posicionou-se contra as proposições do Ministério da Educação e levantou temas importantes como o financiamento das universidades e questões relacionadas ao ensino, pesquisa e extensão. Apesar de logo no início de sua criação se questionar a identidade e finalidade de existência deste grupo de trabalho, o mesmo se desenvolveu e se tornou um grande espaço de discussão sobre a educação superior brasileira. No decorrer de seu desenvolvimento vários vieses de pesquisa foram surgindo, principalmente relacionados às políticas de educação superior nacional, como educação a distância, autonomia universitária, democratização do acesso ao ensino superior público e inserções da universidade na sociedade.

A partir dos trabalhos apresentados e registrados neste grupo, nota-se que há uma pequena abordagem específica de currículo universitário. Tanto relacionado a aspectos mais simples ou complexos de significação curricular. A partir de Lopes e Macedo (2011) se pode afirmar que uma significação mais simples de currículo está relacionada a perceber o mesmo apenas como plano de ensino, programas e grades curriculares. E que uma significação mais complexa vai além disso, relacionando ideologias, práticas e políticas que permeiam os currículos.

Discussões envolvendo sociedade, economia e políticas governamentais aparecem em trabalhos diversos, principalmente discutindo e analisando as influências neoliberais no que se refere à educação superior. Aborda-se a autonomia universitária (MANCEBO, 1997), o financiamento de universidades públicas (SCHWARTZMAN, 1996; LIMA, 2006) e relações entre o ensino superior público e privado (PAGOTTI; ASSIS, 2001). Esses temas discutem políticas, porém não se atrelam às práticas curriculares das universidades.

É fato que as preocupações centrais desse grupo são políticas de educação superior, mas ao desatrelá-las de abordagens curriculares pode-se estar deixando de lado articulações importantes que fazem parte do processo político-decisório para e nas universidades, tanto públicas como privadas. Abordagens e investigações curriculares podem suscitar análises políticas que já estão engendradas nos currículos e discursos dos/sobre os mesmos, assim como verificar que influências estão caracterizando suas transformações e adaptações 
para uma consonância ou não às políticas atuais. Esse tipo de abordagem pode perceber o currículo não como um produto ou resultado de uma política, mas como inerente à própria concepção de determinada política.

Nesse sentido mais complexo de se perceber o currículo universitário é que Alícia de Alba (2002) desenvolve uma extensa pesquisa, onde vai a campo buscar significações que professores curriculistas ${ }^{1}$ de universidades públicas do México têm a respeito de seu trabalho e do próprio currículo. Analisando o discurso de diversos professores curriculistas, ela tece considerações que envolvem principalmente a não preocupação ou concepção superficial quanto às influências neoliberais que envolvem as universidades públicas mexicanas.

Este presente trabalho pretende discutir a obra resultante dessa pesquisa de Alícia de Alba, Curriculum universitario - académicos y futuro ${ }^{2}$, a fim de ressaltar e chamar a atenção para a importância de estudos curriculares do ensino superior brasileiro. Para isto, se fará uma análise comparativa com o único trabalho que faz um estudo semelhante apresentado no GT 11 da ANPEd, Currículo universitário - o que pensam os docentes? (PEREIRA, 2010), assim como com outros trabalhos deste mesmo GT, que não necessariamente fazem alusão direta à currículo, mas que possuem importantes contribuições para uma caracterização política e econômica da realidade do ensino superior no Brasil. Além disso, este trabalho também possui como fonte de análise algumas diretrizes em avaliação da educação superior, estipuladas pelo Instituto Nacional de Estudos e Pesquisas Educacionais - INEP. Permitindo, como já dito, uma abordagem comparativa e crítica da obra mexicana citada e como se pode se apropriar de experiências e conceitos descritos nas realidades brasileiras.

\section{Percepções curriculares de professores universitários mexicanos e brasileiros}

Nesta segunda parte, inicialmente, apresentam-se o contexto de pesquisa e os resultados obtidos na pesquisa de Alícia de Alba, realizada no início dos anos 90, durante o governo de Carlos Salinas de Gortari, conhecido como período salinista ${ }^{3}$. Após, apresentam-se uma descrição do estudo e dos resultados da pesquisa realizada por Elisabete Pereira com professores de uma universidade estadual paulista, no ano de 2006.

Quanto à primeira pesquisa, a questão central de tal estudo foi analisar o

\footnotetext{
1 Professores curriculistas refere-se a professores que realizam atividades curriculares em suas universidades, de acordo com De Alba (2002).

2 Livro de 2002, publicado pela editora Plaza y Valdés Editores, sem tradução para o português.

3 O período salinista, do Presidente Carlos Salinas de Gortaria compreendeu os anos de 1988 à 1994).
} 
discurso de professores universitários que atuassem na área de currículo em seus respectivos trabalhos. Foram escolhidas diversas universidades públicas por todo o México e professores de diferentes áreas do conhecimento, assim como com variadas titulações - mestres, doutores, pós-doutores.

A atuação no campo de pesquisa inicialmente foi composta de aplicação de um questionário fechado simples, para caracterização do professor, com perguntas relacionadas à idade, formação, área de atuação e tempo de trabalho na universidade. Como já dito, foram escolhidos professores que atuavam de alguma forma no currículo de seus cursos ou mesmo no âmbito da universidade. Após a aplicação do questionário, selecionou-se um grupo de professores, onde a maioria possuía altas titulações, um tempo de trabalho médio de 20 anos e já haviam ocupado cargos administrativos.

O segundo passo foi a aplicação de uma entrevista semiestruturada, com este grupo selecionado, composta de quatro abordagens: a) formação do professor no campo do currículo, o que incluía cursos ou mesmo leituras sobre o tema; b) os desafios que o próximo século impunham à sociedade e à formação universitária; c) os problemas que as universidades públicas enfrentavam quanto ao currículo; d) as perspectivas e propostas do professor para o currículo no século XXI.

A análise dos dados foi feita a partir da desconstrução e articulação significativa do discurso, onde a pesquisadora descontruiu os discursos dos professores, permitindo verificar termos e informações não necessariamente ligados ao próprio discurso do professor. Isso permitiu a identificação de significantes flutuantes e vazios. De acordo com a autora, a partir desses significantes pode se identificar concepções e posicionamentos políticos ou mesmo a ausência deles. Em um exemplo citado, um professor, ao responder ao quarto tema semiestruturado, diz que os currículos estão sujeitos às forças das mudanças mundiais, sem explicitar que mudanças são essas. A autora afirma que este é um significante vazio, flutuante, que dependendo de uma abordagem marxista ou neoliberal pode assumir qualquer um desses sentidos. Ou seja, nota-se uma despolitização deste professor.

De Alba (2002) aponta que a maioria dos discursos foi permeada de silêncios e ausências, no que se refere tanto a politização do currículo, como já apontado, quanto a questões sociais, ambientais, culturais e a pobreza. A maioria dos professores atentou somente para questões funcionais do currículo, evidenciando preocupações eficientistas, principalmente relacionadas à evolução/ incorporação das tecnologias e adaptações ao mercado de trabalho. E mesmo quando preocupações sociais e políticas apareciam era de forma não crítica, 
sem perceber as influências neoliberais em suas práticas e nos currículos pelos quais eram responsáveis. Vários professores, por exemplo, se referiam ao fato de que o currículo tinha que permitir com que o aluno percebesse o mundo a sua volta, entendesse a sua sociedade. Porém, nesse mesmo discurso, já era possível notar que essa percepção estava relacionada a preocupações mercadológicas, às necessidades de formações voltadas e filtradas para o mercado de trabalho. Sem preocupações humanísticas, questionadoras ou sociais.

Os muitos silêncios ou opiniões despolitizadas sobre questões sociais relatadas pelos professores são atribuídos por De Alba (2002) ao período pelo qual passava o país durante a realização da coleta dos dados. Neste período, a autora relata uma falsa estabilidade do governo salinista quanto à economia e um bom trabalho de fortalecimento da imagem do próprio governo. Essa falsa estabilidade é relativa a investidas neoliberais, como a abertura de fronteiras comerciais com os Estados Unidos e Canadá e, consequentemente, apoio financeiro destes para o México. A partir dessa parceria o governo investiu no Programa Nacional de Solidariedade (PRONASOL), realizando trabalhos assistencialistas em comunidades pobres mexicanas. Além disso, tudo isso foi muito bem divulgado na mídia, com exorbitantes gastos em propaganda. A falsa estabilidade não era tão facilmente percebida e inclusive o governo foi bastante elogiado pelos bons trabalhos que vinha fazendo junto a camadas pobres e para a economia do país. Ou seja, neste período predominou-se um clima de satisfação, onde as próprias investidas neoliberais eram propiciadoras destes momentos de falsa evolução. E isso, segundo De Alba (2002) refletiu no posicionamento dos professores quanto ao futuro das universidades públicas e de seus currículos. Resultando, como já dito, em posicionamentos despolitizados e projeções curriculares de cunho mercadológico e eficientista.

O segundo trabalho, Currículo universitário: o que pensam os docentes? (PEREIRA, 2010), foi realizado a partir de dados coletados com a aplicação de um questionário on-line aos professores de uma universidade pública paulista, de diversas áreas do conhecimento. O questionário, respondido anonimamente pelos professores, era composto de questões abertas, fechadas e de uma escola de atitudes, escala de Likert. As perguntas iniciais eram voltadas a caracterização do professor, sendo que, a partir dos dados obtidos, concluiu-se que a grande maioria possuía doutorado e era de dedicação integral à universidade, assim como tinham mais de dez anos de trabalho na mesma.

Quanto à análise de conteúdo das questões, abertas e fechadas, foi obtido que a maioria dos professores estava satisfeita com a atual estruturação do currículo, classificando-a como de sólida formação básica, carga horária ade- 
quada, boa distribuição das disciplinas pelo semestre, dentre outras qualidades. Porém, nota-se também a preocupação em se trabalhar ainda mais na direção de um currículo integrado, menos fragmentado, para fortalecer a formação básica. O que vai ao encontro das informações encontradas com a análise da escala likert, onde a formação básica tem mais importância que a formação geral e que, por sua vez, mais importância que a formação profissional, na opinião desses professores.

Ainda com relação à análise de conteúdo das questões abertas e fechadas, quanto à atualidade do currículo, a maioria dos professores não mencionou questões relacionadas à adaptação para necessidades do mercado atual, mas sim, a busca de novas propostas didáticas e novas formas de se desenvolver os cursos. Porém, no que tange à formação dos alunos houve uma grande preocupação em formar os alunos para "novos desafios" (PEREIRA, 2010, p. 6). Nem a autora, e nem os professores de acordo com o relato da mesma, mencionam ou discutem que novos desafios seriam estes. E por isto, considera-se essa informação de forma paradoxal, se comparada ao fato da não preocupação de atualização curricular em virtude de mudanças no mercado de trabalho, como dito por ela, e pelos professores. Esses novos desafios podem ser vistos como significantes flutuantes ou vazios (DE ALBA, 2002), onde não se especifica o que realmente são e podem ser vistos por aspectos díspares, como neoliberais ou marxistas. E que, pelo contexto abordado, podem ser interpretados com vinculações às transformações do mercado de trabalho e com cunho eficientista, por isso o paradoxo. Como exemplificação, há uma grande valorização, por parte dos professores e da própria autora, de intercâmbios para países da união europeia ou com grande desenvolvimento econômico e científico. Onde a "experiência é vista como forma de dialogar com outras culturas e outras perspectivas de profissionalização" (DE ALBA, 2002, p. 6). Assim como "novos desafios", "perspectivas de profissionalização" também pode ser visto como um significante flutuante, que pelo contexto abordado abarca uma forte ligação e admiração de culturas e posicionamentos neoliberais.

Comparando os dois trabalhos, mesmo guardando suas devidas proporções quanto à extensão e duração das pesquisas, nota-se um grande distanciamento entre eles, frente a questões políticas, culturais e sociais. Enquanto no primeiro, como se abordará a frente, a autora levanta a necessidade do envolvimento dessas questões em termos curriculares, no segundo apenas se percebe o currículo quanto instrumental e não se analisa politicamente os discursos que têm em mãos, trabalhando o currículo a partir de um aspecto disciplinar. Mas mesmo com esse distanciamento em termos de abordagens e percepções curriculares 
dos autores, nota-se uma aproximação do posicionamento dos professores. Nos dois trabalhos os professores tratam o currículo de forma despolitizada, e mesmo quando exaltam a importância da formação básica, isso é feito de forma vazia no que tange a aspectos de discussões sociais, políticas e culturais. Em suas falas até aparecem preocupações em ensinar novas culturas, em compreender a sociedade, mas sem posicionamentos críticos frente a esses conhecimentos. O currículo aí serviria somente como esqueleto e base para transmissão de conhecimentos para uma formação, denominada de básica por Pereira (2010).

\section{Temáticas políticas, sociais e econômicas no ensino superior e abordagens curriculares}

Como já abordado nesse trabalho, o GT Política de Educação Superior da ANPEd reúne diversas pesquisas relacionadas à universidade e suas práticas no Brasil. Porém, há poucos trabalhos abordando de forma mais direta o currículo universitário. A seção anterior fez uma análise e uma comparação entre o trabalho realizado por Alícia de Alba e Elisabete Pereira, ambas abordando concepções de professores universitários sobre currículo. O trabalho de Alícia de Alba vai além de uma simples análise de conteúdo das falas obtidas dos professores e expõe diversos aspectos que são necessários às discussões curriculares que não apareceram nessas falas. Discussões políticas, sociais e econômicas atreladas aos currículos são deixadas de lado

$\mathrm{Na}$ terceira parte deste trabalho se partirá de algumas discussões importantes realizadas por Alícia de Alba (2002) que, de acordo com seu posicionamento, devem estar ligadas diretamente às concepções do currículo universitário, tais como o financiamento das instituições públicas de ensino superior e sua privatização e a autonomia universitária e sua avaliação. Esses temas serão analisados de forma comparativa com estudos brasileiros ${ }^{4}$. realizados a partir dessas mesmas temáticas. Chamando a atenção para a importância dessas pesquisas, mas também para sua necessária abordagem com o currículo universitário.

Durante o governo salinista no México existiram diversas políticas voltadas ao ensino superior público. De Alba aponta o FOMES, Fundo para modernização da educação superior, que tinha como princípio investir nas universidades públicas, de modo que as mesmas pudessem se modernizar e se adequar às características dos novos tempos, tanto em termos de mercado como científicas. De Alba afirma um caráter neoliberal nesta política, pois toda a sua proposta

4 A maioria desses estudos foi apresentada, e está registrada, em diversas reuniões anuais do GT Política de Educação Superior da ANPED. 
parte do mercado, de suas exigências e nota-se uma despreocupação com a formação básica, crítica e vinculada a discussões sociais. Ainda no governo salinista, a autora afirma haver um incentivo ao surgimento e fortalecimento de universidades privadas, que teriam a característica de se adequar de forma mais rápida ao mercado, às tendências neoliberais, e de elevar o nível de formação da população mexicana, aliviando a pressão sobre o governo. Ou seja, tanto o investimento, que foi pouco, nas universidades públicas, quanto ao prestígio dado às universidades privadas, favoreceram princípios neoliberais como a ausência do estado, no que diz respeito às políticas educacionais para o ensino superior.

No Brasil, quanto ao financiamento das universidades públicas, nota-se, a partir do trabalho de Schwartzman (1996), um questionamento do governo federal quanto aos investimentos e recursos destinados às instituições federais de ensino superior. O Ministério da Educação afirmava que o custo por aluno de uma universidade pública era muito maior que o custo por aluno em uma universidade privada. O mesmo ministério tentou demonstrar isso ao dividir todo o montante gasto com a manutenção de uma universidade pelo seu número de alunos. Porém, o autor mencionado, desmontou esse cálculo, iniciando com a afirmação de que o governo pegou o montante total composto de custos em ensino, pesquisa, extensão, incluindo manutenção de hospitais, clínicas e outras atividades de assistência social, e dividiu pelo número de alunos. Ou seja, demonstrou que a conta estava errada. Caso ele quisesse saber quanto a universidade custava por aluno, não deveria incluir custos como hospitais universitários ou de assistência social. Nota-se então, que não é só um problema matemático, mas sim, discursivo. Por trás dessa conta está um discurso neoliberal de exaltar que as universidades privadas custam menos para o governo, no que diz respeito ao custo por aluno, e que seria interessante o estado diminuir o seu papel nas públicas para conter gastos. Ou seja, assim como no México, os discursos governamentais quanto aos financiamentos das universidades federais estavam caminhando para o apoio à disseminação das universidade privadas e, consequentemente, à privatização.

Esse caminhar continuou. Em um texto contemporâneo de Rodrigues (2006) há a análise da reforma da educação superior realizada no governo do Presidente Lula. $\mathrm{O}$ autor aborda as diversas facilidades e apoios que o governo federal concedeu aos empresários da educação, ampliando desde 2003, início de seu governo, o número de vagas nas instituições particulares de ensino superior. O discurso do governo é que há poucas vagas nas instituições públicas e que 
mesmo com o plano de ampliação das mesmas, REUNI ${ }^{5}$, não conseguirá atender a demanda que o mercado necessita de profissionais capacitados. Dentre esta democratização do ensino superior, como o próprio governo a chama, há iniciativas como o PROUNI ${ }^{6}$, onde o governo custeia os estudos de alunos carentes em universidades privadas. Assim como em Schwartzman (1996), Almeida (2010) afirma que o discurso do governo quanto ao PROUNI é que é mais barato pagar para um aluno estudar em uma universidade particular do que gerar uma nova vaga em uma universidade federal.

Comparando-se ao México, nota-se que o interesse governamental está cada vez mais voltado ao crescimento do setor privado educacional de ensino superior. Os discursos para a defesa desse argumento são semelhantes, tanto quanto à questão de ser mais barato para o governo custear os alunos nas universidades privadas, ou se ausentar desses custos, quanto também aos benefícios da expansão destas para a população, que poderá se formar e se qualificar melhor para o mercado de trabalho. Assim como, e principalmente, a semelhança dos discursos está em colocar o mercado e a iniciativa privada como balizadores e definidores dos rumos da educação superior.

Além da questão de financiamento das instituições públicas de ensino superior e das iniciativas para suas privatizações, há outros dois fatores, que não se desligam desses, que De Alba (2002) trás para a discussão curricular: a autonomia universitária e suas formas de avaliação.

Quando se trata de autonomia das universidades públicas, tanto mexicanas quanto brasileiras, nota-se uma aproximação de questões relacionadas às suas formas de avaliação ALBA, 2002; MANCEBO, 1997). No México, à época da realização de sua pesquisa, DE Alba relata a criação de uma comissão de avaliação ligada ao governo federal denominada CONAEVA - Comissão nacional para avaliação ${ }^{7}$. Seu mecanismo de funcionamento era realizado em três etapas. A primeira era uma autoavaliação realizada pela universidade, a segunda era uma avaliação realizada por pares, onde uma universidade avaliava outra, e a terceira avaliação era feita por pessoal capacitado indicado pelo governo. Esta última avaliação, segundo a autora, é a que tinha mais peso. Com os dados da avaliação em mãos, o governo passava a controlar o envio de recursos a partir desses dados, se a universidade ia bem na avaliação, recebia mais recursos. Isso acabou se tornando uma forma de coação à autonomia da universidade pública, que passou a ter que se adaptar aos critérios dessa

5 REUNI, sigla para Reestruturação e Expansão da Universidade Federais.

6 PROUNI, sigla para Programa Universidade Para Todos.

7 Tradução minha para CONAEVA - Comissión nacional para la evaluación. 
avaliação. Muitas delas ignoraram este fato e continuaram privilegiando suas autonomias, porém, seus recursos foram diminuídos.

Essa forma de avaliação, como afirma De Alba (2002), acabou implicando diretamente o currículo de algumas universidades, que passaram a se adaptar a esses critérios de avaliação, onde entre eles estavam a modernização da grade para atender às demandas de mercado e às novidades científicas. É curioso notar que vários professores da pesquisa acharam que este tipo de avaliação propiciou excelentes mudanças no currículo, não atentando para a diminuição de sua própria autonomia.

Paralelamente no Brasil, Mancebo (1997) aponta características de uma avaliação das universidades praticada pelo ministério da educação, bastante semelhante a do México. Havia uma autoavaliação e critérios relacionados à quantificação da produção científica, à infraestrutura e à capacidade de realização de objetivos propostos pelo próprio ministério. Como no México, a autoavaliação funcionava como uma forma de consolação para a universidade que estava sendo avaliada. Os outros critérios, como afirma Mancebo, são bastante questionáveis e caminham para a diminuição da autonomia da universidade. A quantificação da produção científica revela interesses neoliberais de produtividade e eficientismo com as federais, obrigando-as a produzir cada vez mais, para valer o grande montante que é investido nas mesmas. A questão da infraestrutura é intrigante, pois o governo julgará a infraestrutura e diminuirá o investimento naquela que estiver ruim, da estrutura que ele próprio montou. Ou seja, o governo transfere para a universidade uma obrigação que é dele. No terceiro critério nota-se uma tentativa de controle sobre a universidade, cerceando sua autonomia, ao designar objetivos que devem ser cumpridos.

Tanto no México, como no Brasil, algumas universidades públicas reagiram às imposições governamentais contra as suas autonomias. Isso foi feito através de greves, ou mesmo na não adoção das proposições indicadas. Hoje, no Brasil, nota-se uma tentativa de abafar certas lutas e questionamentos das universidades públicas com o argumento do REUNI, que está investindo nas mesmas. Porém, é importante salientar que enquanto o REUNI acontece, a expansão das universidades privadas vai ocorrendo bem mais rápida e, junto com ela, a lógica cada vez mais neoliberal da não responsabilidade do governo sobre o ensino superior. Além da própria questão produtivista que permeia as universidades públicas em suas graduações e pós-graduações, estimulando competitividades entre as mesmas na hora de conseguirem benefícios. Pois se uma universidade consegue um bom posicionamento em um ranking pode adquirir mais facilmente bolsas e auxílios, como acontece com o conceito 
capes. Essas características, de certa forma, alteram o currículo universitário e suas práticas.

Após uma análise das formas de financiamentos das universidades públicas e da questão da privatização, assim como de uma discussão sobre autonomia universitária e avaliação, parte-se agora para outros pontos abordados por De Alba (2002) que se relacionam com as diretrizes curriculares de cursos de graduação.

No governo salinista houve uma grande preocupação com a formação do aluno de graduação voltada à sua futura prática profissional e ao mercado de trabalho. Em cursos de licenciaturas, por exemplo, privilegiaram-se os conhecimentos relacionados às disciplinas, no sentido de que o professor dominasse muito bem o assunto que depois iria ensinar. Assim como se deu muita atenção à didática, aos processos de como ensinar e transmitir conhecimentos. Excluiu-se dessa importância, que acabou gerando mudanças em grades curriculares, questões relacionadas à formação social, a questionamentos do processo de ensino e principalmente as noções de currículo enquanto posicionamentos políticos, culturais e sociais. De Alba (2002) aponta ainda que as universidades privadas foram as primeiras a alterar suas grades de disciplinas e seus projetos pedagógicos e que muitas universidades públicas resistiram a essas mudanças. Mas que a pressão governamental é para que elas também adotem esse novo posicionamento.

O Ministério da Educação brasileiro investe no controle de grades curriculares e de conteúdos trabalhados nas universidades há algum tempo. $\mathrm{O}$ provão - exame nacional de cursos - foi uma dessas primeiras tentativas, onde os alunos concluintes de cursos de graduação faziam uma avaliação para verificar a aprendizagem de conteúdos. Este instrumento, que nasceu na segunda metade da década de 1990, existiu até o ano de 2003, quando, no governo Lula, foi criado o SINAES - Sistema Nacional de Avaliação da Educação Superior, criado oficialmente em abril de 2004. Estava incluída em suas providências a alteração da estrutura do provão, criando um outro instrumento denominado ENADE - Exame Nacional de Desempenho de Estudantes. Este foi se tornando, aos poucos, de caráter obrigatório aos concluintes de diversos cursos de graduação. Muitos alunos de universidades públicas o boicotam, indo realizar a prova, mas não a fazendo, o que não acontece geralmente com alunos de universidades privadas, estas que dependem da nota do ENADE para continuar com a chancela de funcionamento de determinado curso. As universidades públicas também dependem da nota ENADE, mas o cerco a elas é bem menor (DANTAS; SOARES; VERHINE, 2006). 
O SINAES instituiu em 2008 o IGC - Índice Geral de Cursos - avaliando os cursos de graduação. O IGC é formado pela nota do ENADE e pela nota de avaliação do curso, que também sofre influência da nota de avaliação da Instituição de Ensino Superior - IES. A nota de avaliação do curso é formada a partir de um formulário que o responsável pelo curso preenche e envia ao INEP. Este mesmo órgão envia representantes, geralmente dois membros cadastrados que são professores de IES, para validar e avaliar as condições reais informadas no formulário enviado ao INEP. A partir disso, os mesmos atribuem uma nota ao curso que está sendo avaliado. Essa nota de avaliação do curso é comparada à nota do ENADE e chega-se a uma média que é a nota do curso, conhecida como conceito do MEC (INEP, 2012a; POLIDORI, 2009).

Tanto a avaliação de cursos pelo INEP, quanto o ENADE tornaram-se mecanismos de controle sobre os currículos universitários nacionais. Mesmo as universidades federais tendo autonomia em não dar atenção a estes mecanismos, há estudos que mostram que, atualmente, até estas já estão atendendo e remodelando seus projetos pedagógicos e currículos a partir, principalmente, do ENADE. Como é o caso da Universidade de Brasília, que tem alterado sua forma de gestão devido a estudos de seus desempenhos no ENADE (PEREIRA, R., 2010). Ou o caso da instituição privada Fundação Getúlio Vargas, que foi buscar no resultado do ENADE respostas para a necessidade ou não de aumento de disciplinas quantitativas em suas grades (CRUZ; FREITAS; SPINOLA, 2009).

O ENADE disponibiliza aos cursos um conteúdo programático do que será avaliado em sua prova. Esses conteúdos abordam aspectos de formação geral, que geralmente englobam noções de cidadania, violência e política, assim como aspectos de formação específica de cada curso (INEP, 2012b). A intenção aqui não é levantar aspectos significativos, discursivos e políticos dessas escolhas de conteúdos, apesar de isto ser importante e poder gerar um outro estudo. A preocupação, relacionada à questão curricular, é que ao se apresentar um conteúdo programático dizendo o que cairá ou não no ENADE, pode ser o mesmo que dizer para os cursos não perderem seu tempo com outros assuntos, mas sim, se dedicarem aos que são apresentados. Pois, o desempenho dos alunos de um curso dependerá do conhecimento desses referidos assuntos. Esse direcionamento, que também se pode chamar, de cerceamento de autonomia, pode alterar não só o currículo como todo o processo de gestão de um curso ou universidade. Provavelmente, as particulares tomarão primeiro essas providências, pois se não tomarem podem ter cursos fechados por um mal desempenho no ENADE. As públicas, que desde o início dos mecanismos 
de avaliação, se mostram resistentes, estão aos poucos caminhando para essa unificação curricular determinada pelo ministério da educação.

Finaliza-se este trabalho, se chamando a atenção para o currículo universitário, não só em termos de mudanças de grades curriculares, mas como meio de se perceber outras grandes mudanças que estão ocorrendo na universidade pública. Tanto no que diz respeito à concepção de autonomia e da aceitação cada vez mais tranquila da privatização das universidades ou do pagamento para se estudar nelas, como já acontece nos cursos de pós-graduação lato sensu. Fazer uma ponte de estudo e pesquisa com a realidade mexicana, mesmo que de há 20 anos atrás, nos mostra o quanto os países pobres estão interligados por políticas comuns de cunho neoliberal. Olhar para trás 20 anos e em uma outra realidade, permite perceber o quanto essas políticas tem avançado, e de forma silenciosa, nos cotidianos universitários públicos. O estudo de Alícia De Alba, abordado nesse trabalho, deveria e poderá servir de inspiração para uma análise curricular complexa de nosso panorama universitário, estimulando pesquisas e discussões no citado GT-11 da ANPEd, importante espaço de discussão de educação superior. Espera-se com este trabalho suscitar a realização de outros, com pesquisas de campo, ou mesmo de documentos curriculares, tendo como referência a abordagem complexa realizada por Alícia De Alba. Pois o currículo pode ser um espaço de resistência, mas como já dito, não apenas na defesa de esta ou aquela grade curricular, mas na defesa de uma ideologia libertária que permeia a condução e gestão curricular das universidades públicas brasileiras.

\section{Referências}

ALMEIDA, Wilson. O PROUNI e a "democratização do ensino superior": explorações empíricas e conceituais. In: REUNIÃO ANUAL DA ANPEd: educação no Brasil: o balanço de uma década, 33, 2010, Caxambu, MG. Anais... Rio de Janeiro: ANPEd, 2010. Disponível em: <http://www. anped11.uerj.br/OPROUNI.pdf $>$. Acesso em: 20 jul. 2012.

CRUZ, Breno; FREITAS, Antônio; SPINOLA, Ana Tereza. Estrutura curricular e ENADE: há uma correlação positiva e significativa entre o percentual de disciplinas quantitativas em um curso de administração e a nota do curso no ENADE? In: ENCONTRO DE ENSINO E PESQUISA EM ADMINISTRAÇÃO E CONTABILIDADE, 2, Curitiba, 2009. Anais... Rio de Janeiro: ANPAD, 2009. Disponível em: <http://ebape.fgv.br/sites/ebape. fgv.br/files/estrutura.pdf $>$. Acesso em: 17 ago. 2012. 
DANTAS, Lys; SOARES, José; VERHINE, Robert. Do Provão ao ENADE: uma análise comparativa dos exames nacionais utilizados no Ensino Superior Brasileiro. Ensaio, Rio de Janeiro, v. 14, n. 52, 2006.

DE ALBA, Alicia. Curriculum universitário - académicos y futuro. México/UNAM: Plaza e Valdés, 2002.

FÁVERO, Maria de Lourdes. O GT de Educação Superior: origens, desenvolvimento e produção. In: REUNIÃO DA ANPEd: educação: manifestos, lutas e utopias, 25, 2002, Caxambu, MG. Anais... Rio de Janeiro: ANPEd, 2002. Disponível em: <http://www.anped11.uerj.br/ indexatual.html>. Acesso em: 20 jul. 2012.

INEP - Instituto Nacional de Estudos e Pesquisas Educacionais. Portaria Normativa $\mathbf{n}^{\mathbf{0}} \mathbf{4 0}$ de 12 de dezembro de 2007. Disponível em: <http:// portal.inep.gov.br/educacao-superior/indicadores $>$. Acesso em: 17 ago. 2012a.

INEP - Instituto Nacional de Estudos e Pesquisas Educacionais. Manual do ENADE. 2004. Disponível em: < http://portal.inep.gov.br/enade>. Acesso em: 17 ago. $2012 b$.

LIMA, Katia. Financiamento da educação superior brasileira nos anos de neoliberalismo. In: REUNIÃO DA ANPEd: educação, cultura e conhecimento na contemporaneidade: desafios e compromissos, 29, 2006, Caxambu, MG. Anais... Rio de Janeiro: ANPEd, 2006. Disponível em: $<$ http://www.anped11.uerj.br/indexatual.html $>$. Acesso em: 20 jul. 2012.

LOPES, Alice; MACEDO, Elizabeth. Teorias de currículo. São Paulo: Cortez, 2011.

MANCEBO, Deise. Autonomia universitária: reformas propostas e resistência cultural. In: REUNIÃO DA ANPEd: educação, crise e mudança: tensões entre a pesquisa e a política, 20, 1997, Caxambu, MG. Anais... Rio de Janeiro: ANPEd, 1997. Disponível em: <http://www.anped11.uerj.br/ indexatual.html >. Acesso em: 20 jul. 2012.

PAGOTTI, Antônio; ASSIS, Sueli. O ensino superior no Brasil: entre o público e o privado. In: REUNIÃO DA ANPEd: intelectuais, conhecimento e espaço público, 24, 2001, Caxambu, MG. Anais... Rio de Janeiro: ANPEd, 2001. Disponível em: $<$ http://www.anped11.uerj.br/indexatual.html $>$. Acesso em: 20 jul. 2012. 
PEREIRA, Elisabete. Currículo universitário: o que pensam os docentes? In: REUNIÃO ANUAL DA ANPEd: educação no Brasil: o balanço de uma década, 33, 2010, Caxambu, MG. Anais... Rio de Janeiro: ANPEd, 2010. Disponível em: $<\mathrm{http}: / /$ www.anped11.uerj.br/indexatual.html $>$. Acesso em: 20 jul. 2012.

\section{PEREIRA, Rodrigo. As repercussões do ENADE na gestão das} universidades públicas brasileiras - o caso da UnB. 2010. $147 \mathrm{f}$. Dissertação (Mestrado) - Universidade de Brasília, Brasília, 2010. Disponível em: <http://repositorio.unb.br/bitstream/10482/7365/1/2010_ RodrigodaSilvaPereira.pdf > . Acesso em: 17 ago. 2012.

POLIDORI, Marlis. Políticas de avaliação da educação superior brasileira: Provão, SINAES, IDD, CPC, IGC, e... outros índices. Avaliação, Campinas; Sorocaba, v. 14, n. 2, 2009.

RODRIGUES, José. Os empresários do ensino e a reforma da educação superior do governo Lula da Silva. In: REUNIÃO DA ANPEd: educação, cultura e conhecimento na contemporaneidade: desafios e compromissos, 29, 2006, Caxambu, MG. Anais... Rio de Janeiro: ANPEd, 2006. Disponível em: <http://29reuniao.anped.org.br/trabalhos/trabalho/GT09-2023--Int.pdf>. Acesso em: 20 jul. 2012.

SCHWARTZMAN, Jacques. Políticas de ensino superior no Brasil na década de 90: o financiamento das universidades federais. In: REUNIÃO DA ANPEd: a política de educação no Brasil: globalização e exclusão social, 19, 1996, Caxambu, MG. Anais... Rio de Janeiro: ANPEd, 1996. Disponível em: <http://www.anped11.uerj.br/19/SCHWARTZ.htm>. Acesso em: 20 jul. 2012.

Dostoiewski Mariatt de Oliveira Champangnatte Universidade do Grande | Rio Rio de Janeiro | RJ | Brasil. Contato: dostoiewski.tico@gmail.com 
